\title{
Resolution of post burn hypo pigmentation and scar by homeopathic medicines
}

\author{
Swami Shraddhamayananda* \\ Ramakrishna Mission Medical Unit, Belur Math, Howrah, West Bengal, India
}

\begin{abstract}
Burn injuries are common domestic, occupational as well as industrial injuries resulting from trivial to life threatening lesions in the body. Post-burn healing of skin often accompanied by hypopigmentation, contracture, and hypertrophic changes and thus is associated with serious disfigurement and functional impairment as well. Although conventional treatments are much improved in recent years, however, they are beyond reach of most of these patient's due to high cost and absence of infrastructural facilities. In this study two low cost homeopathic medicines graphitis and causticum were used to treat post-burn scar and hypo pigmentation in 100 patients resulting complete remission in 82 cases. In the remaining 18 cases, more than $20 \%$ improvement was seen in 10 cases and 8 cases did not follow up after first visit. In this experiment 10 control cases were also followed up where only placebo treatment is given. They showed no change of their lesions. Present state of knowledge regarding the mechanism of action of these medicines is extremely meager; however, encouraging results in these posts burn difficult complicated cases prompted us to expose these findings before scientific fraternity for appraisal.
\end{abstract}

\section{Introduction}

Healing of a burn is largely unpredictable. Multiple new cellular processes and molecules have been introduced in recent times to treat burn injuries [1-14]. Experimental studies in molecular biology and transgenic animal models created a scope of further exponential improvement $[15,16]$.

Although survival from severe burn injuries improved a lot, however, treatment of scarring has not improved alongside survival [17]. At present, there is no definite treatment of scarring and thus many patients suffering from burn injuries have to undergo long term medical care for their scar, hypopigmentation, contracture, hypertrophic changes, keloid formation etc. Besides some general treatments like massage and use of moisturizing agents, pressure garments, silicone sheeting, topical as well as intralesional steroids, and experimental therapies such as interferon, skin grafting and different types of flaps are used for the reconstruction of contractures. Thus autograft, human allograft, fresh, frozen and glycerolized porcine xenograft, in vitro cultured keratinocytes, dermal regenerated template ( biological raw materials), dermal analogue of bovine collagen covalently linked to chondroitin-5- sulphate, epidermal analogue of silicon, biodegradable collagen dermal analogue, adipose tissue, fetal cells, embryonic stem cells, platelets, placental and amniotic fluid cells, stem cells, nanoparticles are only a few examples which are used in burn wound management [1-14].Againdyspigmentation particularly hypopigmentation in the scars is a common phenomenon due to disturbance of melanogenesis [18]. This may lead to social humiliation and sometimes isolation of the affected person [19-21]. Laser therapy (vascular-specific pulsed dye laser, ablative fractional $\mathrm{CO}_{2}$ laser) is also an important step in hypopigmented scars where it increases pigment formation in melanosomes [22]. Nonablative fractional resurfacing has also been studied which resulted in overall improvement in $90 \%$ of subjects [23]. However, laser therapy requires multiple treatment procedures and it is a painful procedure. Surgical excision, dermabration and application of melanocytes in the affected area.
Over 95\% fire-related burns occur in low- and middle-income countries where no modern treatments are available and as a consequence they are more likely to be thrown into further poverty [24]. It is also estimated that 10 million DALYs (Disability adjusted life years) occur globally each year due to fire related burns [25]. In India where this study was done over $1,000,000$ people are moderately or severely burnt every year (WHO,2014).In 2008, over 410, 000 burn injuries occurred in the United States of America, with approximately 40,000 requiring hospitalization [26].

The principle of homeopathy is that if an agent produces specific symptoms in healthy persons when taken orally then those symptoms producing diseases can be cured by ultra-diluted homeopathic medicine prepared with that agent. Homeopathic principle is based on the theory that bioactive potency is more in lower concentrations of matter and therefore, very small quantity would suffice to readjust altered homeostasis in human body. There are many interesting papers published in peer reviewed journals where different theories regarding action of homeopathic medicines have been described. The most accepted theory is a clathrate model of action- in which specific organization of solvent can retain and maintain at least some properties of the original medicine leading to 'mind-body' interactions which can be studied by dielector or differential scanning colorimetric measurements $[27,28]$. At present studies on molecular chaperones, signal transduction pathways, specific ligand-binding activity etc' are going on which may through light in this hitherto controversial areas of science. In this study homeopathic medicines "graphites 1000" and

Correspondence to: Swami Shraddhamayananda, Ramakrishna Mission Medical Unit, Belur Math, Howrah, West Bengal, India, Tel: 91-9143415986; E-mail: gopalmj.belurmath@gmail.com

Key words: healed burn injury, hypopigmentation, homeopathy, repigmentation, dissolved scar

Received: July 01, 2017; Accepted: July 24, 2017; Published: July 27, 2017 
"causticum 1000" were tested to find out if there is any efficacy of them in resolution of post-burn hypo pigmentation and scarring.

\section{Methods}

\section{Aims and hypothesis}

Aims of this study was to examine whether low cost ( $<\$ 5$ per patient) easily available homeopathic medicines is effective in post burn scar and hypo pigmentation. This study was considered important by me as thousands of people are presently suffering from these conditions particularly in developing countries as they cannot afford modern costly treatment schedules and in many cases all conventional treatments fail. Only oral homeopathic medicines were used (no external application) every 15 days interval. So, patients' complaints were good.

\section{The patient recruitment and selection}

This is an ongoing study from 2002 through 2017. Most of the patients came after at least one year of conventional treatment. A total of 100 patients were enrolled in this study. No scoring was done as it is still controversial and also because we could not determine which was the actual scoring method to be followed in this study. Written informed consent was taken from all patients and from parents in minor subjects following the approved consent form of the Institutional Ethical Committee which given approval of this study. Follow ups of all the patients were done by consultant dermatologists attached to the medical unit who assessed the improvements and given final opinion regarding complete remission of the disease. In this study 10 cases were enrolled as control cases where treatment was given only with placebo which contained only vehicle of the medicine. Details of these cases are given in supplementary Table 1 and Figure 1.

Chronological photography was done of each cases only when we saw the changes in lesion comparing the previous one, usually 2-3 months interval.

\section{Methodology and parameters}

The homeopathic medicine "Graphites 1000" (ultra-diluted graphite) was used for resolving the scar tissue and another homeopathic medicine "Causticum 1000" (ultra-diluted potassium hydroxide) was used for repigmentation following homeopathic Materia Medica. These medicines were selected according to clinical experience during treatment of other diseases by these medicines and observing beneficial effects of these medicines on any burn injury if this was associated with the original disease. These medicines were prepared following Indian Pharmacopeia and were purchased from an authorized company "HAPCO" (Hahnemann Publishing Co. Pvt. Ltd, Kolkata, India). The medicine was prepared by the company according to standard procedures mentioned in Homeopathic Pharmacopoeia of India (Ministry of Health, Government of India, 1971, document 1:1). Homeopathy medicines are prepared from plants, animal tissue,

Table 1. Different types of lesions and their predominant sites.

\begin{tabular}{|l|l|l|l|}
\hline Single lesions & \multicolumn{2}{|l|}{ Multiple lesions } & No. of cases \\
\hline Site & No. of cases & Sites & 30 \\
\hline Finger/hand & 18 & Hand, forearm, arm & 12 \\
\hline Foot & 10 & Hand, neck, chest & 8 \\
\hline Chin & 2 & Chest, arm & 4 \\
\hline Forehead & 6 & Leg, thigh & 6 \\
\hline & & Finger, face & 4 \\
\hline & & Face, foot & 64 \\
\hline Total & 36 & & \\
\hline
\end{tabular}

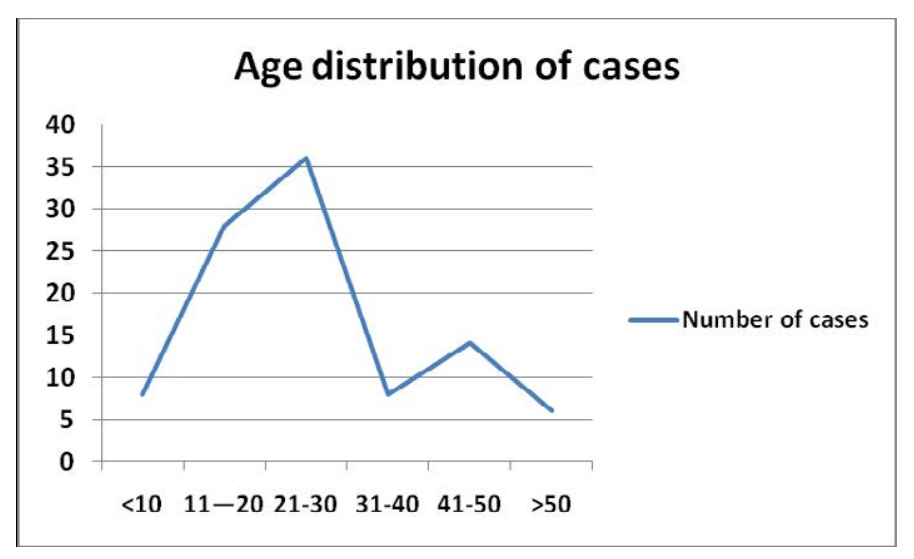

Figure 1. Age distribution of the cases.

microorganisms, inorganic and organic chemicals in ultra-diluted concentrations. The graphites, a mineral in the form of carbon atoms which are arranged in a honeycomb lattice. The name Graphite is derived from the Greek term 'grahein' which means 'to write' because this form of carbon constitutes the major part of pencils. It is mainly used in industries as polishes, lubricants, batteries etc. In homeopathy, it is used to treat different ailments especially the skin diseases like localized rough, hard, persistent dryness of skin unaffected by eczema. The homeopathic medicine Graphites is prepared by serially pulverizing pure graphite powder with lactose. In homeopathic dispensaries potassium hydrate a distillate prepared from slaked lime and potassium sulphate is used as the medicine causticum. Otherwise pure potassium hydroxide which is available as white, deliquescent crystals may be used in preparation of the medicines following approved pharmacopoeia (Indian pharmacopoeia in this study). Commercial potassium hydroxide as pellets is used in bleaching, soap making etc. It is used in homeopathy when the skin is tense and stretched, as in post burn scars with or without burning pain, to treat blisters and eruptions of the skin besides treatment of diseases of other organs [29].

Causticum and Graphites both were given only orally (no external application) alternately and once in 2 weeks period as both contracture/ scarring and hypo pigmentation was present in all the cases. This schedule of treatment was followed in all the cases irrespective of differences of age, sex, degree of lesion, because these medicines are completely free of any side effects due to ultra-dilutions.

\section{Intervention and its standardization}

In this study intervention was applied at individual levels. The target population was patients with post burn scar and/or hypopigmentation who were not benefitted by conventional treatment even after six months of therapy. Inclusion criteria of the enrolled patients were absence of local or common systemic evidences of acute inflammation, there was no associated local or systemic disease and general health parameters were within normal limits. Exclusion criteria were evidences of acute inflammation, presence of any other associated disease, general health parameters were not within normal limits and pregnancy in women subjects. A separate control group was maintained which were followed up for some periods as given in supplementary Table 1, however, they were treated later considering suffering of the patients and there was possibility of development of mental depression as observed in different studies [20,21] which seemed to me unethical. As the medicine was administered orally separating lesions as experimental and control groups in multiple lesion patients was also not possible. Resolution of the scar contracture was considered when 
there was at least $80 \%$ improvement of the original restricted motion judged by the clinicians. A CONSORT diagram is given showing the flow of participants through each stage of the study.

\section{Outcome measurements}

Biopsy examination in post burn scar cases was not done for aesthetic reasons, however, Pre- and Post-treatment biopsy were done in 6 cases from areas of hypo pigmentation only. Serial photographs were recorded in all the cases in separate file and identification numbers. Simple percentile analysis was done for assessment.

\section{Results}

Most of the patients aged between 11-30 years (64.0\%, Figure 1) with slightly higher $(56.0 \%)$ partaking of female patients and most of them presented with deep lesions (84.0\%), Single lesions were present in $36(36.0 \%)$ cases and multiple lesions were present in remaining 64 $(64.0 \%)$ cases (Table 1$)$. In single lesions finger/hand was commonly affected $(50.00 \%)$ followed by foot $(27.77 \%)$; in multiple lesions Hand, forearm, arm was affected in most of the cases (47.62\%) followed by hand, neck, chest involvement in $28.57 \%$ cases. $54.0 \%$ cases participated in this study after 6 months to one year of conventional treatments without any improvements, similarly $38.0 \%$ cases and $8.0 \%$ cases enrolled in this study after $>1-4$ years and $>4$ years of similar treatments without any benefit (Figure 2).

Among 100 patients there was complete remission in $82(82.0 \%)$ cases. In the remaining 18 cases, more than $40 \%$ improvement was seen in 12 cases and six cases did not continue treatment after $1^{\text {st }} / 2^{\text {nd }}$ visit. After beginning of treatment earliest reaction was noted within one month and complete remission which was observed in 82 cases occurred in between 6 months and 4 years. In $51.0 \%$ cases duration of homeopathic treatments was less than one year, similarly in $38.0 \%$, $8.0 \%$ and $3.0 \%$ cases durations of homeopathic treatments were $1-2$ years, $>2-3$ years and $>3-4$ years respectively (Figure 3 ).

Five typical cases with post-burn complications have been shown in serial photographs from beginning of treatment to complete recovery (Figures 4-8). Pre- and Post-treatment biopsy were done in 6 cases from post burn hypo pigmented areas (for aesthetic reasons biopsy was not taken from other parts), and in all these cases pretreatment biopsy showed no melanocytes but post treatment biopsy sections showed melanocytes and melanin pigments.

Ten control cases showed no changes during their follow up periods.

\section{Duration of conventional treatment without improvement}

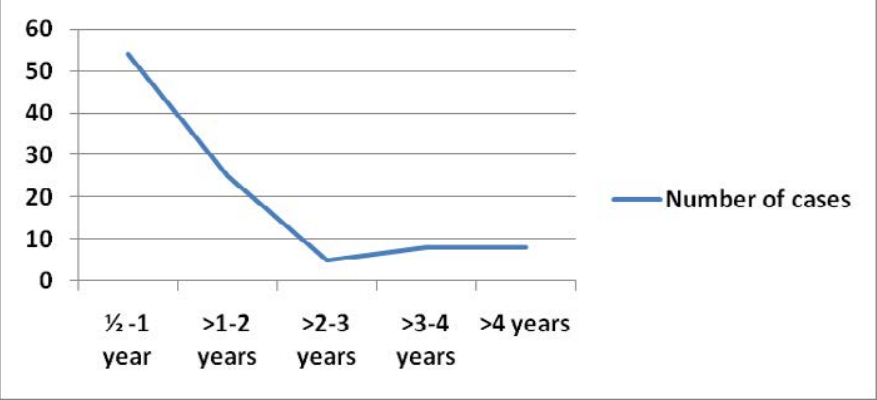

Figure 2. Duration of conventional treatments without any benefit before homeopathic treatments.

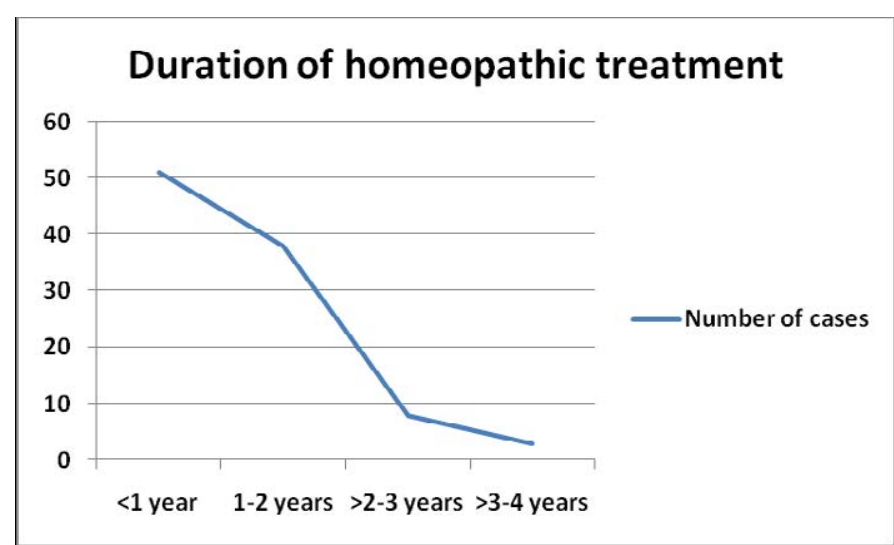

Figure 3. Duration of homeopathic treatments given to the patients.
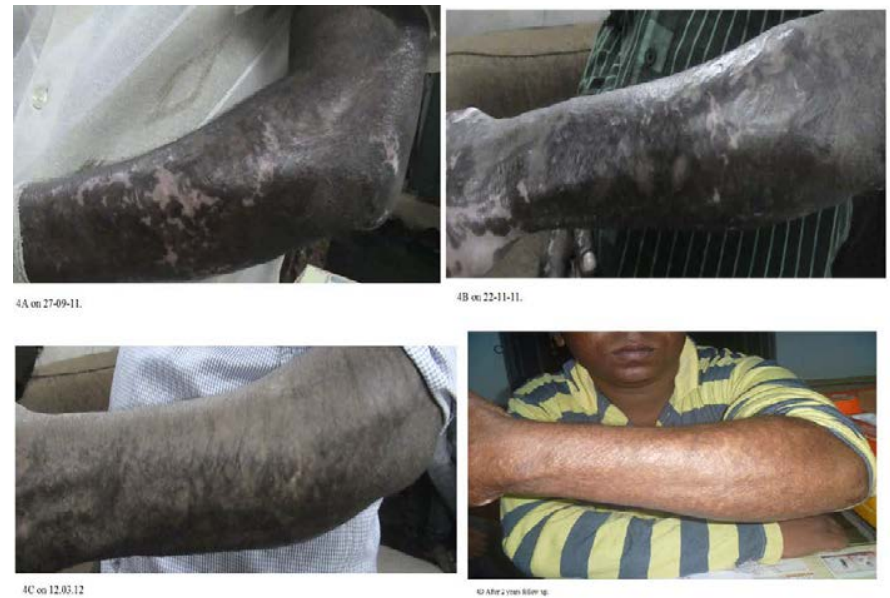

Figure 4A-4D. Extensive post-burn complication on left forearm has been shown in serial photographs from beginning of treatment to complete recovery.
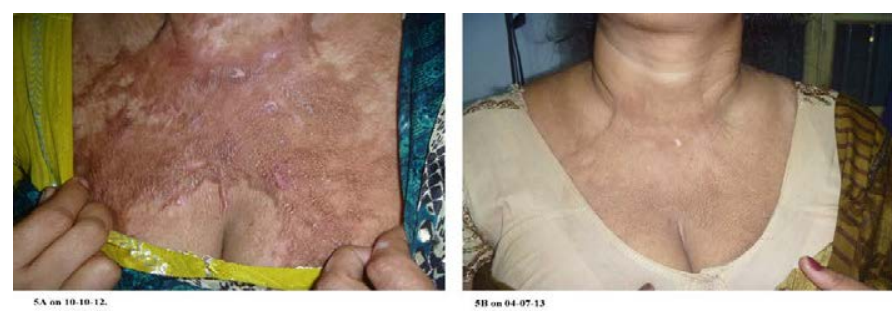

Figure 5A-5B. Extensive post-burn contracture on chest with restricted neck movement has been shown in two photographs at beginning of treatment and after complete recovery.

\section{Discussion}

Apart from a study of Cantharis in the early treatment of minor burns [30] there is no authentic study on burn wound healing in pubmed which in view of the current interest in alternative remedies like (Graphitis) homeopathy appears exceptional and thus it was thought reasonable to assess the effects of some homeopathic medicines on persisting post burn scar and hypo pigmentation after conventional treatments. In this study, I selected two important homeopathic medicines graphites and causticum as in my medical practice I observed that post burn scars sometimes heal secondarily when patients treated with these medicines for other diseases.

A vast spectrum of injuries can occur from a burning accident, from trivial to some of remarkable injuries. Burn can damage in a number of ways, but by far the most common organ involved is the 

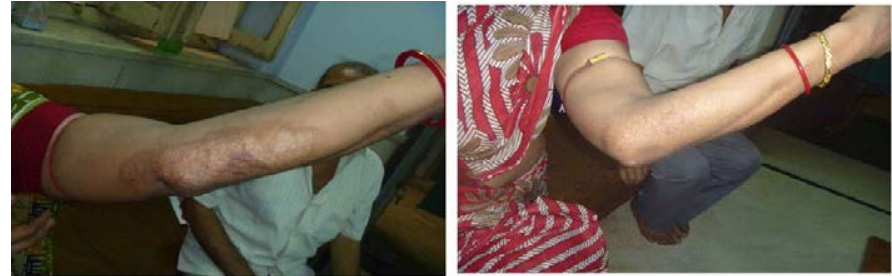

6A on 19-09-12

6B on 08-02-12.

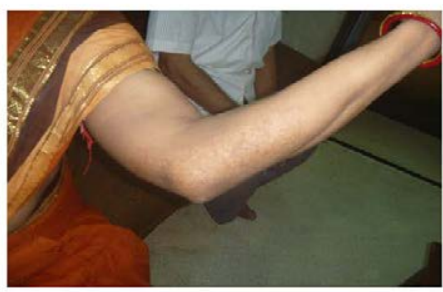

6C After 1 year follow up.

Figure 6A-6C. Post-burn complication on left forearm including elbow joint and with restricted motion has been shown in serial photographs from beginning of treatment to complete recovery.

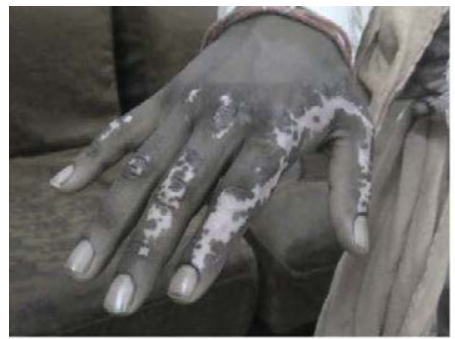

7A on 27-09-2011.

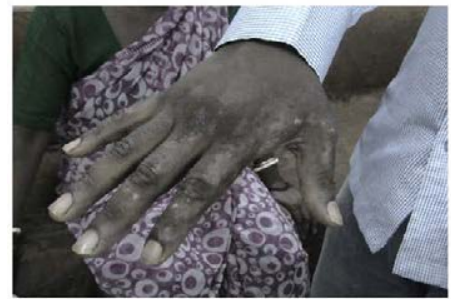

7C 19.06-2012

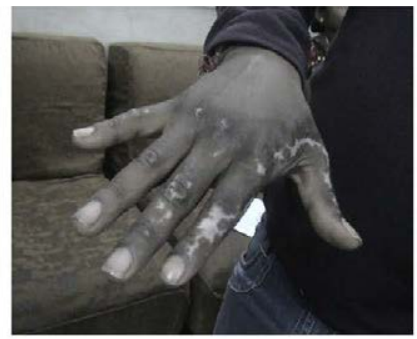

7B on 22:11-2011.

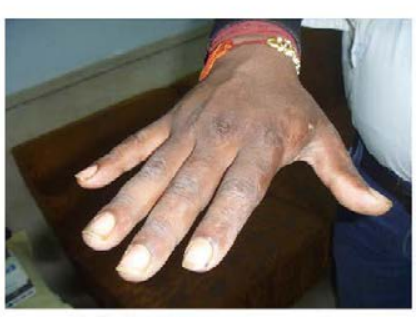

TD After 2 ys follow up
Figure 7A-7D. Post-burn complication on right hand with prominent vitiligo and restricted motion has been shown in two photographs from beginning of treatment to complete recovery.

skin. Treatment and prognosis of burn depends on depth of burn. A heal burn patient may be left with scar and having various degree of functional and aesthetic components.

Deep burn heals by scaring and often results in hypopigmentation, which has similar psychological impact on the patient as that of vitiligo. This not only causes severe disfigurement at times this is associated with functional impairment as well. It has been observed that these changes can induce serious magnitude of depression.

Among different studies on post burn scarring, the risk factors included dark skin, female sex, young age, burn site on neck and/or upper limbs, multiple surgical procedures, meshed skin graph, time to healing, and burn severity [31,32]. In this study female sex, young age, burn site on neck and/or upper limbs were also found more in the enrolled patients under this study.

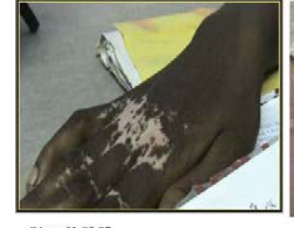

8A on $31-15.67$

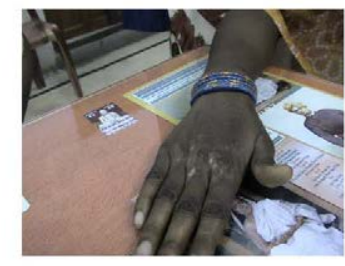

SD on 01-04-07

в8
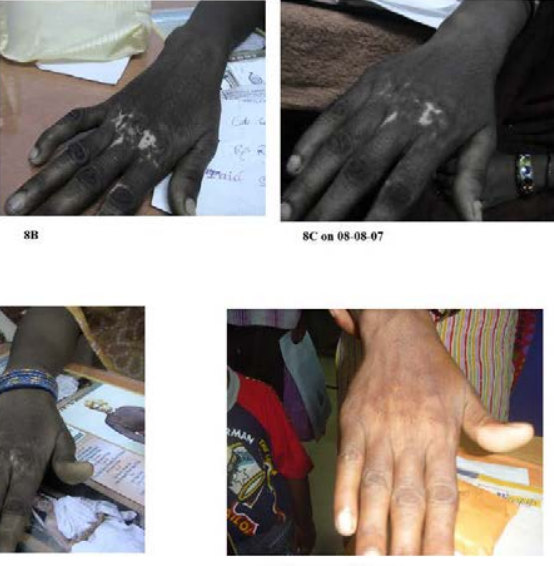

BE after 4 years follow up

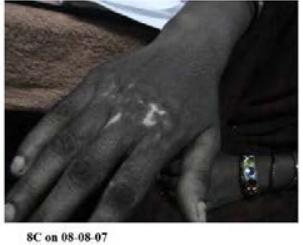

$8 \mathrm{C}$ 0n 08.08 .07
Figure 8A-8E. Post-burn complication on right hand with prominent vitiligo and restricted motion has been shown in five photographs from beginning of treatment to complete recovery.

As of now surgical management in the form of tissue grafting has been accepted to treat post-burn hypopigmentation. It can be minimized by various physical therapy and plastic surgical procedure but not eliminated completely. The appearance of even the best split - skin grafted areas and the donor sites of these grafts is also a "scar" by the patients' definition of a scar. So, surgical options are limited, expensive, and often the results are sub optimal and beyond the reach of a large number of patients affected with this. On the other hand, this study shows very encouraging results by homoeopathic medicines, which is not only cost effective ( $<\$ 5 /$ patient) but it could dissolve fibrosis and restore the pre-injury status in most of the cases. We have treated post burn vitiligo patients with other medicines where vitiligo was very prominent and patients opted for treatment of vitiligo only [33]; where we observed no improvement of contracture if present in those patients, thus this method of treatment is specifically effective on post burn contractures.

\section{Conclusion}

Post burn contractures and hypopigmentations were treated with two low cost homeopathic medicines which showed encouraging results. Thus, this may help thousands of suffering humanity in developing countries who cannot afford modern treatment for their treatment.

\section{Conflict of interest}

There is no conflict of interest in this paper.

\section{Acknowledgement}

I hereby acknowledge The President, Ramakrishna Mission for giving me permission to publish this paper. I also thank Dr. Satadal Das and all doctors and paramedical staff of our Medical Unit for helpful suggestions.

\section{References}

1. Halim AS, Khoo TL, Mohd Yussof SJ (2010) Biologic and synthetic skin substitutes: An overview. Indian J Plast Surg 43: S23-28.[Crossref]

2. Gentile P, De Angelis B, Pasin M, Cervelli G, Curcio C B, et al. (2014) Adipose-derived stromal vascular fraction cells and platelet-rich plasma: basic and clinical evaluation for cell-based therapies in patients with scars on the face. J Craniofac Surg 25: 267-72.

3. Klinger M, Caviggioli F, Klinger F M, Giannasi S, Bandi V, et al. (2013) Autologous fat graft in scar treatment. J Craniofac Surg 24: 1610-1615. 
4. Huang L, Burd A (2012) An update review of stem cell applications in burns and wound care. Indian J Plast Surg 45: 229-236.[Crossref]

5. Rigo C, Ferroni L, Tocco I, Roman M, Munivrana I, et al. (2013) Active silver nanoparticles for wound healing. Int J Mol Sci 14: 4817-4840.[Crossref]

6. Hudson DA, Renshaw A (2006) An algorithm for the release of burn contractures of the extremities. Burns 32: 663-668.[Crossref]

7. Wainwright DJ, Bury SB (2011) Acellular dermal matrix in the management of the burn patient. Aesthet Surg J 31: 13S-23S.[Crossref]

8. Sheridan RL, Choucair RJ (1997) Acellular allogenic dermis does not hinder initial engraftment in burn wound resurfacing and reconstruction. Journal of Burn Care and Rehabilitation 18: 496-499.

9. Bianco P, Robey PG (2001) Stem cells in tissue engineering. Nature 414: 118-121. [Crossref]

10. Kaviani A, Perry TE, Dzakovic A, Jennings RW, Ziegler MM, et al. (2001) The amniotic fluid as a source of cells for fetal tissue engineering. Journal of Pediatric Surgery 36:1662-1665.

11. Kaviani A, Perry TE, Barnes CM, Oh JT, Ziegler MM, et al. (2002) The placenta as a cell source in fetal tissue engineering. J Pediatr Surg 37: 995-999.[Crossref]

12. Jones I, Currie L, Martin R (2002) A guide to biological skin substitutes. Br J Plast Surg 55: 185-193.[Crossref]

13. Shakespeare PG (2005) The role of skin substitutes in the treatment of burn injuries. Clin Dermatol 23: 413-418.[Crossref]

14. De Coppi P, Bartsch G Jr, Siddiqui MM, Xu T, Santos CC, et al. (2007) Isolation of amniotic stem cell lines with potential for therapy. Nat Biotechnol 25: 100-106. [Crossref]

15. Aderounmu AO, Omonisi AE, Akingbasote JA, Makanjuola M, Bejjde RA, et al. (2013) Wound-healing and potential anti-keloidal properties of the latex of Calotropis procera (Aiton) Asclepiadaceae in rabbits, Afr J Tradit Complement Altern Med 12: 574-579.

16. Ren HT, Hu H, Li Y, Jiang HF, Hu XL, et al. (2013) Endostatin inhibits hypertrophic scarring in a rabbit ear model. J Zhejiang Univ Sci B 14: 224-230.[Crossref]

17. Sheridan RL (2003) Burn care: results of technical and organizational progress. JAMA 290: 719-722.[Crossref]

18. Tyack ZF, Pegg S, Ziviani J (1997) Postburn dyspigmentation: its assessment, management, and relationship to scarring--a review of the literature. J Burn Care Rehabil 18: 435-440.[Crossref]
19. Hoogewerf CJ, van Baar ME, Middlekoop E, van Love NE (2014) Impact of facial burns: relationship between depressive symptoms, self-esteem and scar severity. Gen Hosp Psychiatry 36:271-276.

20. Nitescu C, Calota DR, Stancioiu TA, Marinescu SA, Florescu IP, et al. (2012) Psychological impact of burn scars on quality of life in patients with extensive burns who received allotransplant. Rom J Morphol Embryol 53: 577-583.

21. Wisely JA, Hoyle E, Tarrier N, Edwards J (2007) Where to start? Attempting to meet the psychological needs of burned patients. Burns 33: 736-746.

22. Khandelwal A, Yelvington M, Tang X, Brown S (2014) Ablative fractiona photothermolysis for the treatment of hypertrophic burn scars in adult and pediatric patients: A single Surgeon's experience. J Burn Care Res (In press).

23. Waibel J, Wulkan AJ, Lupo M, Beer K, Anderson RR (2012) Treatment of burn scars with the 1,550 nm nonablative fractional Erbium Laser. Lasers Surg Med 44: 441-446. [Crossref]

24. WHO (2008) Burn prevention and care, World Health Organization, Geneva.

25. WHO (2002)The injury chartbook: A graphical overview of the global burden of injuries, World Health Organization, Geneva.

26. WHO (2014) Burns, World Health Organization, Geneva.

27. Kuda-Bakhsh AR (2003) Towards understanding molecular mechanisms of action of homeopathic drugs: An overview. Molecular and Cellular Biochemistry 253: 339-345.

28. Bell I R, Koithan M (2012) A model for homeopathic remedy effects: low dose nanoparticles, allostatic cross - adaptation and time dependent sensitization in a complex adaptive system. BMC Complementary \& Alternative Medicine 12: 191.

29. Dewey WA (2013) Essentials of Homoeopathic Materia Medica and Homoeopathic Pharmacy. Forgotten Books, London.

30. Leaman AM, Gorman D (1989) Cantharis in the early treatment of minor burns. Arch Emerg Med 6: 259-261.[Crossref]

31. Lawrence JW, Mason ST, Schomer K, Klein MB (2012) Epidemiology and impact of scarring after burn injury: a systematic review of the literature. $J$ Burn Care Res 33 : 136-146.[Crossref]

32. Gangemi EN, Gregori D, Berchialla P, Zingarelli E, Cairo M, et al. (2008) Epidemiology and risk factors for pathologic scarring after burn wounds. Arch Facial Plast Surg 10: 93-102.[Crossref]

33. Shraddhamayananda S (2013) Vitiligo - a treatise of successful homeopathic treatment, Lambert Academic Publishing, Germany pp. 24-77.

Copyright: (C2017 Shraddhamayananda S. This is an open-access article distributed under the terms of the Creative Commons Attribution License, which permits unrestricted use, distribution, and reproduction in any medium, provided the original author and source are credited. 